\title{
FACTORS RESPONSIBLE FOR PREMATURE DISCONTINUATION OF LONG ACTING REVERSIBLE CONTRACEPTIVES - A STUDY CONDUCTED IN MODEL FAMILY PLANNING CLINIC OF DHAKA MEDICAL COLLEGE HOSPITAL OVER A PERIOD OF ONE YEAR
}

\author{
MEHZABIN $\mathrm{S}^{1}$, KUTUBI A ${ }^{2}$, ELAHI MM $^{3}$, BAR D $^{4}$, MANNI UJA $^{5}$, ISLAM M${ }^{6}$
}

\begin{abstract}
Background: Despite the improvement in availability and utilization of Long Acting Reversible Contraceptive (LARC) methods which comprises intrauterine contraceptive devices(IUCD) and implants, premature discontinuation is becoming a public health concern and its consequence may lead to failure of a program. Therefore identifying the causal factors are important for designing a strategy to overcome the problem.
\end{abstract}

Objectives: To measure discontinuation of intrauterine contraceptive device (IUCD) and implants and identify baseline characteristics associated with premature discontinuation.

Materials and Methods: This retrospective study was conducted among the clients attended in Model Family Planning Clinic of Dhaka Medical College Hospital from January,2018 to December, 2018. Records of all clients who discontinued LARC prematurely (before device expiration) and clients who wished for discontinuation but did not do so during this period were explored.

\begin{abstract}
Results:Total 233 implants were removed during the study period among them 87 were removed before their expiry date. Total 252 clients came for early removal (within 1 year of insertion) of cuT but only 39 were removed. On the other hand 82 clients came for premature discontinuation(after 1 year of their insertion) during this period, among which 18 were removed before the date of expiry. Side effects associated with the method itself and the procedure, expulsion, failure and other similar inconveniences contributed for discontinuation.

Conclusions: Higher level of discontinuation of LARC may substantially contribute to high fertility rate, unwanted pregnancies and induced abortions. Also, premature termination makes the method less cost effective. Therefore appropriate counseling, follow up care and management of side effects along with information on contraceptive effectiveness, insertion and removal procedure are very important.
\end{abstract}

Keywords: premature discontinuation, long acting contraceptive device.

\section{Introduction}

In recent decades, contraceptive prevalence has increased in low income countries, become more diversified and shifted toward a stronger reliance on modern methods. ${ }^{1,2}$ As new methods are introduced, men and women have more options to choose a method that meets their preferences throughout the family planning (FP) life cycle and contraceptive prevalence tends to increase. ${ }^{3}$

1. Dr. Shahfinaz Mehzabin, Medical Officer, Model Family Planning Clinic, Dhaka Medical College Hospital

2. Dr. Afroza Kutubi, Professor, Obs and Gynae Department, Institute of Child and Mother Health

3. Dr. Mohammad Mahbub Elahi, Resident Surgeon, General Surgery, Dhaka Medical College Hospital

4. Dr. Debashish Bar, Registrar, Department of Surgery, Dhaka Medical College Hospital

5. Dr. Umme Jamila Akther Manni, Assistant Professor, Department of Community Medicine, Dhaka Medical College, Dhaka, Bangladesh

6. Dr. Mazharul Islam, Junior Consultant Medicine, Dhaka Cantonment, Dhaka

Correspondence: Dr. Shahfinaz Mehzabin, Medical Officer, Model Family Planning Clinic, Dhaka Medical College, Hospital, Dhaka, Bangladesh. Mobile No- 01711206469, E-mail: shafinaz.mehzabin@gmail.com

Received: January 20, 2019

Revision: February 20, 2019

Accepted: 15 Mach 2019 
Despite increased use of FP, need for contraceptive is still strikingly high and is estimated at about 222 million women and approximately 1 in every 4 women in developing countries in 2012.3,4 The World Health Organization (WHO) recommends waiting at least two years after delivery before attempting to conceive again. Long term contraceptive methods enable women and couples to cost effectively avert pregnancy during these risky time periods by allowing women to space and/ or limit births. 5,6

Long-acting reversible contraceptive methods(LARC) typically include intrauterine contraceptive devices(IUCD) and implants. Although LARCs are not medically indicated for all women or the appropriate choice for all couples, these two methods offer an important form of protection for couples to space and limit births for longer periods of time than most other modern methods. LARC methods may be a good option for couples who want to delay pregnancy for a longer period or limit any future pregnancies but who are not committed to a permanent method. Since LARCs do not contain estrogen, they are generally compatible with breastfeeding. ${ }^{7,8}$

The American College of Obstetricians and Gynecologists has recommended LARC methods as first line contraceptive options for both adults and adolescents. ${ }^{9,10}$ However concerns among health care providers about rapid discontinuation of LARC methods, especially among adolescent, may discourage use. ${ }^{11}$ Our objective was to identify factors associated with and baseline characteristics of premature discontinuation of LARC. In this study we also tried to find out the solution for premature discontinuation of LARC.

\section{Materials and methods:}

This is an observational study which was conducted among the clients attended in Model Family Planning Clinic of Dhaka Medical College Hospital who came to discontinue LARC before their expiry date. The study period was from January,2018 to December, 2018. Records of all clients who discontinued LARC prematurely (before device expiration) and clients who wished for discontinuation but did not do so during this period were explored.

\section{Results:}

For the purposes of this study we classify the clients who discontinue before their expiry of LARC into discontinuation while still in need (DWSIN) and discontinuation due to no further need groups.

Discontinuation while still in need (DWSIN) includes the clients who discontinue LARC when they still need a family planning method but they discontinue due to side effects of the methods.

\section{Discontinuation due to no further need} includes the clients who discontinue LARC when they do not need family planning methods.

Table-I

Frequency and percentage of premature discontinuation of LARC by type:

\begin{tabular}{lcc}
\hline LARC type & $\mathrm{N}$ & $\%$ \\
\hline Implants & 104 & 65.82 \\
IUCD & 54 & 34.18 \\
\hline
\end{tabular}

Among 158 clients who removed LARC prematurely, 104 were implants and 54 were IUCD. So rate of premature removal of implants were $65.82 \%$ and IUCDs were $34.18 \%$.

Table-II

Time of removal of LARC according to type

\begin{tabular}{lccc}
\hline LARC type & $\begin{array}{c}\text { Total no of } \\
\text { premature removal }\end{array}$ & $\begin{array}{c}\text { Removal within 1 } \\
\text { year of insertion }\end{array}$ & $\begin{array}{c}\text { Removal after 1 year } \\
\text { of insertion }\end{array}$ \\
\hline Implants & 104 & 36 & 68 \\
IUCDs & 54 & 39 & 15 \\
\hline
\end{tabular}

Among 104 clients who removed implants prematurely, 36 clients removed within one year of insertion and 68 clients removed after one year of insertion but before date of expiry. On the other hand 39 clients removed IUCDs within one year of insertion and 15 clients removed after one year of insertion but before date of expiry. 
Table-III

Relation of early discontinuation of LARC with educational qualifications:

\begin{tabular}{lccc}
\hline LARC type & $\begin{array}{c}\text { Total number of } \\
\text { removal }\end{array}$ & $\begin{array}{c}\text { Number of women } \\
\text { who did not } \\
\text { complete secondary } \\
\text { school }\end{array}$ & $\begin{array}{c}\text { Number of women } \\
\text { who completed } \\
\text { secondary school or } \\
\text { higher than that }\end{array}$ \\
\hline Implants & 104 & 77 & 27 \\
IUCDs & 54 & 39 & 15 \\
\hline
\end{tabular}

Early discontinuation of LARC was more common among the clients who did not complete secondary school (77:27 and 39:15 respectively for Implants and IUCDS)

Table-IV

Reasons for discontinuing implants (DWSIN):

\begin{tabular}{lcc}
\hline $\begin{array}{l}\text { Causes of premature removal } \\
\text { of implants }\end{array}$ & $\begin{array}{c}\text { Total number of removal } \\
\text { within } 1\end{array}$ & $\begin{array}{c}\text { Tear of insertion number of removal } \\
\text { after 1 year of insertion }\end{array}$ \\
\hline $\begin{array}{l}\text { Menstrual abnormality in the form of } \\
\text { menorrhagia or irregular per vaginal bleeding }\end{array}$ & 21 & 32 \\
Weight gain & 00 & 03 \\
Local swelling & 01 & 02 \\
Discomfort (without any reason) & 01 & 02 \\
Without any reason & 03 & 00 \\
Pain at insertion site & 00 & 01 \\
Generalized weakness & 01 & 01 \\
\hline
\end{tabular}

Among the reasons for discontinuing implants (DWSIN), menstrual abnormality in the form of menorrhagia or irregular per vaginal bleeding was most common (within 1 year-21, after 1 year32). Other causes were Weight gain (3), local swelling (3), discomfort without any reason (3) without any reason (1)\& pain at insertion site (2).

Table-V

Reasons for discontinuing implants (Discontinue while no further need):

\begin{tabular}{lcc}
\hline $\begin{array}{l}\text { Causes of premature removal } \\
\text { of implants }\end{array}$ & $\begin{array}{c}\text { Total number of removal } \\
\text { within } 1\end{array}$ & $\begin{array}{c}\text { Total number of removal } \\
\text { after 1 year of insertion }\end{array}$ \\
\hline Desire for pregnancy & 06 & 18 \\
Husband abroad & 02 & 03 \\
Husband death & 00 & 04 \\
Divorce & 00 & 01 \\
Hysterectomy & 01 & 01 \\
\hline
\end{tabular}

Among the reasons for discontinuing while no further need, desire for pregnancy was most common (within 1 year-06, after 1 year-18). Other causes were husband abroad (5), husband death (4), divorce (1) and hysterectomy (2). 
Table-VI

Reasons for discontinuing IUCDs (DWSIN)

\begin{tabular}{lcccc}
\hline $\begin{array}{l}\text { Causes for wishing to } \\
\text { discontinue }\end{array}$ & $\begin{array}{c}\text { Total number } \\
\text { of clients came } \\
\text { to remove } \\
\text { within 1 year } \\
\text { of insertion }\end{array}$ & $\begin{array}{c}\text { Total number } \\
\text { of actual } \\
\text { removal of Cu } \\
\text { T within 1 year } \\
\text { of insertion }\end{array}$ & $\begin{array}{c}\text { Total number } \\
\text { of clients came } \\
\text { to remove } \\
\text { after 1 year of } \\
\text { insertion }\end{array}$ & $\begin{array}{c}\text { Total number } \\
\text { of actual }\end{array}$ \\
$\begin{array}{l}\text { Teval of Cu } 1 \text { year } \\
\text { of insertion }\end{array}$ \\
\hline Irregular per vaginal bleeding & 44 & 02 & 11 & 00 \\
Menorrhagia & 45 & 04 & 07 & 01 \\
Lower abdominal pain & 29 & 00 & 10 & 01 \\
without any reason & 15 & 05 & 06 & 00 \\
Displaced Cu T & 17 & 17 & 02 & 02 \\
Leukorrhoea & 15 & 00 & 04 & 00 \\
Amenorrhoea & 06 & 00 & 01 & 00 \\
husband's dissatisfaction & 05 & 02 & 00 & 00 \\
Vaginitis & 04 & 00 & 00 & 00 \\
Dyspareunia & 03 & 00 & 00 & 00 \\
Weight gain & 01 & 00 & 02 & 00 \\
Generalized weakness & 01 & 00 & 00 & 00 \\
Feeling thread in vagina & 02 & 00 & 00 & 00 \\
PID & 02 & 02 & 02 & 00 \\
Polymenorrhoea & 00 & 00 & 20 & 00 \\
Missing thread & 40 & 00 & 03 & 00 \\
Expulsion of Cu T & 04 & 00 & 00 & - \\
\hline
\end{tabular}

Total number of clients came for a wish to discontinue IUCDs while still in need (DWSIN) within one year of insertion were 233. Among them only 32 were removed due to different reasons. Irregular per vaginal bleeding was the most common reason (within 1 year-44, after 1 year-11) for wishing to discontinue IUCDs while still in need (DWSIN). Actual removal of Cu-T was 39 and the most common cause of removal was displacement of $\mathrm{Cu} \mathrm{T}$ (within 1 year-17, after 1 year-02).

Table-VII

Reasons for discontinuing IUCDs (Discontinue while no further need):

\begin{tabular}{lcccc}
\hline $\begin{array}{l}\text { Causes for } \\
\text { wishing to } \\
\text { discontinue }\end{array}$ & $\begin{array}{c}\text { Total number of } \\
\text { clients came to } \\
\text { remove within 1 } \\
\text { year of insertion }\end{array}$ & $\begin{array}{c}\text { Total number of } \\
\text { actual removal } \\
\text { of Cu T within 1 } \\
\text { year of insertion }\end{array}$ & $\begin{array}{c}\text { Total number of } \\
\text { clients came to } \\
\text { remove after 1 } \\
\text { year of insertion }\end{array}$ & $\begin{array}{c}\text { Total number of } \\
\text { actual removal } \\
\text { of Cu within 1 }\end{array}$ \\
\hline $\begin{array}{l}\text { Desire for pregnancy insertion } \\
\text { Husband abroad }\end{array}$ & 05 & 05 & 10 & 10 \\
Menopause & 04 & 02 & 00 & 00 \\
Pregnancy & 00 & 00 & 01 & 01 \\
\hline
\end{tabular}

Total number of clients came for a wish to discontinue IUCDs while no further need were 24 (within 1 year-13, after 1 year-11) but the actual number of IUCD removal was 18 (within 1 year7 , after 1 year-11). The most common reason of wish to discontinue IUCD was desire for pregnancy (15) and it was also the common cause of IUCD removal (15). 


\section{Discussion:}

Contraceptives are used by the majority of married or in-union women in almost all regions of the world. Modern contraceptive methods constitute both IUCD and hormonal implants. The proportion of women using LARC methodsIUCD and implants - has increased worldwide over the last few decades. ${ }^{1,12}$ Long acting reversible contraceptives are best preferences for most women for delaying or spacing births as because of its less side effects, less failure rate and it is technically easy for insertion and removal. In order to avoid financial barriers for use many countries like Bangladesh provide the service free of cost, which created additional opportunity, moreover Bangladesh government gives incentives to clients and health care provider for LARC. ${ }^{13,14}$

We studied among married women who came to Model Family Planning Clinic, Dhaka Medical College Hospital for premature discontinuation of IUCD and implants. The main reasons for discontinuation of implants while still in need are menstrual abnormality in the form of irregular per vaginal bleeding or menorrhagia. On the other hand the main reasons for discontinuation of IUCDs while still in need is menorrhagia, irregular per vaginal bleeding and cramping pain in lower abdomen.

Causes of discontinuation due to no further need includes desire to become pregnant, marital dissolution, husband abroad or death of husband, hysterectomy and menopause. The reasons for discontinuation of implants due to no further need include desire for pregnancy, husband's death, husband living abroad, divorce. The reasons for discontinuation of IUCDs due to no further need include desire for pregnancy, husband living abroad, menopause and pregnancy.

From previous studies it was reported that significant proportion of women discontinue long acting contraception use within a short period of time. The discontinuation rate varies from country to country. In this study educational status was revealed as a predictor to early removal of Implants. Illiterate women were more likely to remove Implants early as compared to those whose educational level was secondary and more. This result was contradictory with the previous study done in Debre Markos, but was supported by a study done in Durame town. ${ }^{15,16}$ This might be due to the reason that those women with higher educational level can understand the possible side effect of the method and able to coupe the method by comparing this with the benefit.

Similar to other previous studies this study also shows that women who experienced Implant side effect were more likely to remove the methods early as compared to those who didn $1 / 2 \mathrm{t}$ experience a side effect. ${ }^{17,18}$ This might be due to the fact that, side effects directly affect women tolerance and use which precipitate them to change the method or withdraw from Implant use. On the other hand social taboo, misconception about Implants and lack of proper pre-insertion counseling, particularly about the expected side effects raise the discontinuation habit of many women in need of removal.

Regarding IUCD, this study found a strong association between IUCD discontinuation and side effects. There was also a strong association between follow-up practice and IUCD discontinuation. Place of residence, sex of last child and reproductive intention were also associated with IUCD discontinuation. The results found in this study are consistent with the result of previous studies. ${ }^{16,17}$

Previous reported findings ${ }^{17,18,19}$ suggest that in case of IUCDs, side effects and health concerns were the most common reason for discontinuation. This study has also found that side effects as the major reason for IUCD discontinuation and experience of side effect was found strongly associated with IUCD discontinuation. This study also found that IUCD discontinuers returned for fewer or no follow-up visits when compared with continuers. Those who had never made any follow-up visits were more likely to discontinue IUCD use than those who had made some follow-up visits.

This study has several programmatic implications. First, the high rate of discontinuation related to side effects need to be more openly discussed and properly 
addressed. Second, follow-up service within a period of few months after insertion is very crucial to minimize and prevent device expulsion failure.

\section{Limitations:}

- The study was conducted in a public hospital which may not reflect the socioeconomic and educational status of clients of entire country.

- Use of only quantitative method was also another limitation of the study.

- This study was done only in a small number of population. Large studies are needed for any inference.

\section{Conclusion:}

Side effects associated with LARC itself and the procedure, expulsion, failure and other similar inconvenience contributed for discontinuation of LARC making the method less cost effective. Therefore proper client selection, appropriate counseling, follow up care and management of side effects along with information on contraceptive effectiveness, insertion and removal procedures are very important. Due to the numerous benefits of LARC, IUCDs and the implant should be considered as first-line contraceptive options among all women to reduce unintended pregnancy. This early discontinuation study, along with future research in this area can help policy makers and program managers track family planning progress and foster them to meet the goal of reproductive health for all.

\section{References}

1. Bertrand, J.T., T.M. Sullivan, E.A. Knowles, M.F. Zeeshan, and J.D. Shelton. 2014. "Contraceptive Method Skew and Shifts in Method Mix in Low-and Middle-Income Countries." International Perspectives on Sexual and Reproductive Health 40 (3):144-153.

2. Seiber, E.E., J.T. Bertrand, and T.M. Sullivan. 2007. "Changes in Contraceptive Method Mix in Developing Countries." International Family Planning Perspectives 33 (3):117-123.

3. Ross, J., and J. Stover. 2013. "Use of Modern Contraception Increases when More Methods Becom Available: Analysis of Evidence from 1982-2009." Global Health: Science and Practice 1(2):203-212.
4. Singh, S., G. Sedgh, and R. Hussain. 2010. "Unintended Pregnancy: Worldwide Levels, Trends, and Outcomes." Studies in Family Planning 41 (4):241250.

5. Conde-Agudelo, A., A. Rosas-Bermúdez, and A.C. Kafury-Goeta. 2006. "Birth Spacing and Risk of Adverse Perinatal Outcomes: A Meta-Analysis." Journal of American Medical Association 295(15):1809-1823.

6. Conde-Agudelo, A., A. Rosas-Bermúdez, and A.C. Kafury-Goeta. 2007. "Effects of Birth Spacing on Maternal Health: A Systematic Review." American Journal of Obstetrics and Gynecology 196(4):297-308.

7. Rutstein, S.O. 2005. "Effects of Preceding Birth Intervals on Neonatal, Infant and Under-Five YearsMortality and Nutritional Status in Developing Countries: Evidence from the Demographic andHealth Surveys." International Journal of Gynecology \& Obstetrics 89 (1):S7-S24.

8. Rutstein, S.O. 2008. Further Evidence of the Effects of Preceding Birth Intervals on Neonatal Infant and Under-Five-Years Mortality and Nutritional Status in Developing Countries: Evidence from the Demographic and Health Surveys. DHS Working Papers No. 41. Calverton, Maryland, USA:Macro International. Available at: http://www.dhsprogram.com/pubs/ pdf/WP41/WP41.pdf.

9. American Congress of Obstetricians and Gynecologists. Committee option No. 450: Increasing use of contraceptive implants and intrauterine devices to reduce unintended pregnancy. Obstet Gynecol. 2009;114:1434-1438.[PubMed:20134301]

10. American Congress of Obstetricians and Gynecologists. Committee Opinion No.539: Adolescents and long-acting reversible contraception: implants and intrauterine devices. Obstet Gynecol. Oct;2012 120(4):983-988.[PubMed: 22996129]

11. Kavanaugh ML, Frohwirth L, Jerman J, Popkin R, Ethier K. Long-acting reversible contraception for adolescents and young adults: patient and provider perspectives. J Pediatr Adolescents Gynecol. 2013; 26:86-95. [PubMed: 23287602]

12. Darroch, J.E. 2013. "Trends in Contraceptive Use."Contraception 87 (3):259-263.

13. United Nations, Department of Economic and Social Affairs, Population Division (2015). Trends in Contraceptive Use Worldwide 2015 (ST/ESA/SER.A/ 349).

14. Scoggins \& Bremner (2016). FP2020 momentum at the midpoint 2015-2016. http://progress. familyplanning2020.org/.54. USAID. Contraceptive 
Use and Discontinuation Patterns in Nepal: Norplant, IUCD, Pill, and Injectables.EngenderHealth, 2003. http://www. engenderhealth.org/files/pubs / familyplanning/nepal_report_on contraceptive_use.pdf)

15. Ali M, Cleland J. Contraceptive discontinuation in six developing countries: a cause-specific analysis.Int Fam Plan Perspect. 1995;21:92-97.

16. Chowdhury AI, Fauveau V, Aziz KM. Effect of child survival on contraception use in Bangladesh.J Biosoc Sci. 1992;24:427-432.
17. Asari VG. Determinants of contraceptive use in Kerala: the case of son/daughter preference. $J$ FamWelfare. 1994;40:19-25.

18. Bhat PN, Halli SS. Factors influencing continuation of IUCD use in South India: evidence from amultivariate analysis. J Biosoc Sci. 1998;30:297319.

19. Salhan S, Tripathi V. Factors influencing discontinuation of intrauterine contraceptive devices: anassessment in the Indian context. Eur J Contracept Reprod Health Care. 2004;9:245-259. 